\title{
Distributed pedagogical leadership functions in Early Childhood Education settings in Finland
}

\author{
Johanna Heikka ${ }^{1}$, Katja Suhonen ${ }^{2}$ \\ School of Applied Educational Science and Teacher Education, \\ University of Eastern Finland, 80100, Joensuu, Finland ${ }^{1}$ \\ MAEd, Project Researcher, School of Applied Educational Science and Teacher Education, \\ University of Eastern Finland, 80100, Joensuu, Finland ${ }^{2}$ \\ johanna.heikka@uef.fi' ${ }^{1}$,katja.suhonen@uef.fi ${ }^{2}$
}

DOI: https://doi.org/10.37134/saecj.vol8.no2.4.2019

Received: 05 Ogos 2019; Accepted: 04 November 2019; Published: 03 December 2019

\begin{abstract}
The topic of distributed pedagogical leadership has attracted researchers' interest in early childhood education leadership. A growing body of research focuses on investigating leadership enacted between directors and teachers in ECE settings. This small-scale study aimed at identifying the functions of distributed pedagogical leadership in ECE and understanding the interdependence of leadership enactments by the centre directors and ECE teachers within ECE settings. Data on the perceptions of six ECE professionals, two ECE centre directors, two ECE teachers and two child care nurses on distributed pedagogical leadership were collected via individual interviews and written documents. The results indicated that the studied ECE professionals perceived the core functions of distributed pedagogical leadership as constructing shared visions, goals and mutual values between centre staff, developing ECE pedagogy within the centre, facilitating learning and expertise of educators, building the operational structures and the culture of the centre and enhancing efficient and participative decision-making within centres. Within all the five functions of distributed pedagogical leadership, the leadership enactment included responsibilities at both the centre level enacted by the centre directors, and at the team level enacted by the ECE teachers. All the five functions were operated within ECE centres in a way in which they had separate but interdependent leadership responsibilities. The study clearly indicated that the teachers played an active role in leading pedagogical development in their teams, and teacher leadership worked as a mediator of pedagogical leadership within the whole centre.
\end{abstract}

Keywords: early childhood education; leadership; distributed pedagogical leadership; teacher leadership; interdependence

\section{INTRODUCTION}

Interest in investigating ECE leadership from distributed perspectives has increased recently (Aubrey, 2016; Boe \& Hognestad, 2017; Male \& Palaiologou, 2017; Sims, Forrest, Semann, \& Slattery, 2015; Waniganayake, Cheeseman, Fenech, Hadley, \& Shepherd, 2017). Contemporary research suggests that distributed forms of leadership can assist in reaching the goals set for ECE by supporting organisational change and pedagogical development, enhancing professional development, and advancing curriculum reform in ECE settings (Heikka, Waniganayake, \& Hujala, 2013; Waniganayake, Rodd, \& Gibbs, 2015).

Findings (Aubrey, 2016; Ho, 2011; Waniganayake et al., 2017; Waniganayake, Heikka, \& Halttunen, 2018) indicate that in ECE settings, responsibilities for pedagogical 
leadership are typically enacted between leaders and teachers. These processes are, however, influenced by implementation of distributed leadership and teachers' skills and positions in enacting pedagogical leadership in their teams. ECE teachers are typically not well prepared to lead pedagogical development in their teams (Heikka, Halttunen, \& Waniganayake, 2016; Waniganayake et al., 2015). In addition, previous findings indicated that teachers lack authority, power and support for their leadership (Alila et al., 2014; Halttunen, 2009; Heikka, 2014). However, new findings indicate that distributed enactment of leadership responsibilities with ECE teachers is highly anticipated among ECE professionals in Finland (Heikka, Halttunen, \& Waniganayake, 2018).

In Finland, ECE leadership stakeholders usually work in geographically dispersed locations. An ECE centre director usually leads a cluster of 2-3 centres. This is one reason for distributing pedagogical leadership and for emphasising teachers' roles in pedagogical leadership in their own teams. In such contexts, a leadership approach that creates interdependence between ECE centre directors and teachers through the shared construction and enactment of visions and strategies is even more crucial. Centre directors are responsible for developing a common operational culture in their centres. This involves pedagogical leadership, the development of early childhood education and assessment systems, as well as educators' professional competence and working conditions (EDUFI, 2016).

This study emerged from the Finnish ECE policy reforms that have taken place in the past few years. The new law for early childhood education (540/2018) and the National Core Curriculum for Early Childhood Education and Care (EDUFI, 2016) made ECE teachers responsible for pedagogy in their staff teams, usually including one or two child care nurses. According to the new legislation, along with the teacher the team can also include a social educationalist specialised in ECE and an additional staff member, such as a child care nurse. The pedagogical responsibility of the teachers includes the planning, development and assessment of teaching in their child groups (EDUFI, 2016). ECE teachers have a three-year Bachelor of Education degree from a university and social educationalists have a Bachelor of Social Sciences from a university of applied sciences. Child care nurses have a vocational qualification in social welfare or health care.

In distributed pedagogical leadership, the concepts of distributed leadership and pedagogical leadership are combined (Heikka, 2014). This combination includes the core element of distributed leadership, which is that pedagogical leadership is separately enacted by formal and informal leaders but interdependently through organisational contexts (Spillane, Halverson, \& Diamond, 2001; Spillane, 2006). Interdependence in enacting leadership responsibilities by centre directors and the teachers within an ECE centre is crucial to achieve common goals. In distributed pedagogical leadership approach, leadership context is considered as a constitutive element of leadership enactment. Spillane et al. (2001) emphasise the meaning of organisational structure, tools and routines, culture, language, and so on as situational elements in distributed leadership. Furthermore, Spillane, Diamond and Jita (2003, p. 537) and Spillane (2006, p. 60) state that leadership tools, like test results, curriculum materials, and observation documents not only assist leaders in their work but are actually the "core elements of leadership" as they guide the enactment of leadership. For example, evaluation forms contribute to the practice of leadership.

Based on Thompson's (1967) examination of interdependencies, Spillane (2006, p. 60) identifies three types of distributed leadership: "collaborated distribution", "collective distribution", and "coordinated distribution". All of these forms include interdependence between leaders in enacting leadership responsibilities. In collaborated distribution, 
persons share the time, place, tasks, and goals, whereas in collective and coordinated distribution, persons are working separately but are interdependently enabling each other's work in achieving common goals. In coordinated distribution, the shared task (e.g., evaluation) is accomplished by following sequences of actions.

Heikka (2014) has identified five dimensions of distributed pedagogical leadership in the ECE organisation that create interdependence between the enactment of leadership by different stakeholders. The first dimension, enhancing shared consciousness of visions and strategies between stakeholders, understands pedagogical leadership as a dynamic process that involves ECE professionals within one municipality in a shared construction of the understanding of visions and strategies. Active participation in the negotiation and planning processes of pedagogy can enhance participants' capacity to make informed decisions on pedagogy. Similarly, the involvement of different stakeholders in shared cognitive processes brings relevant information from diverse perspectives to the basis of developmental decisions. Similarly, Sims et al. (2015), state that the essence of distributed leadership is the mutual understanding of meaning of the organisation by all staff members.

Distributing responsibilities for pedagogical leadership involves macro-level municipality leaders who provide sufficient resources for enacting pedagogical leadership within centres and creating structures within which the efficient enactment of pedagogical improvement at the centres is realised. Support from the macro level also includes making pedagogical leadership visible and accountable by employing evaluation tools for pedagogical improvement. For micro-level leadership, this dimension includes teachers' participation in pedagogical leadership. Pedagogical leadership at the team level can be promoted by focusing on the roles and responsibilities of the ECE teachers within pedagogical team processes. This entails teachers taking responsibility for pedagogy and guiding the planning and assessment of pedagogical practices within their teams, according to plans that are jointly formulated (EDUFI, 2016).

Teachers' involvement in leadership has recently been conceptualised within the framework of distributed leadership. Teacher leadership means that the ECE teacher performs the functions and responsibilities expected of a leader (Harris, 2003). Teacher leadership functions and responsibilities discussed in global research studies include leading the curriculum and pedagogy, organising daily activities in the children's groups, arranging the division of labour in the teams, coordinating collaboration with parents, enhancing pedagogical development, guiding pedagogical practices in the teams, and supporting the team members' professional learning. In addition to team-level leadership tasks, the teacher cooperates and participates in decision-making at the centre level with the centre director and with the teachers from other groups (Colmer, Waniganayake, \& Field, 2015; Harris, 2003; Heikka et al., 2016, 2018; Ho, 2011; Hognestad \& Boe, 2014, 2015; York-Barr \& Duke, 2004).

The third dimension, distributing and clarifying power relationships between the stakeholders, includes enhancing centre directors' and teachers' participation in decisionmaking about developmental proceedings in municipalities (Heikka \& Hujala, 2013). Achieving efficiency in pedagogical leadership also demands a distribution of authority between centre directors and teachers. The leaders can promote the teachers' role as pedagogical leaders by providing sufficient tools and commonly constructed strategies for pedagogical development. The authority is shared as the teachers work independently but interdependently as pedagogical developers in their own child groups. The centre directors are to guide and develop the leadership tasks of the teachers in parallel with the goals and pedagogical principles of the centre and the municipality. 
Distributing the enactment of pedagogical improvement within centres involves designing distributed leadership functions between centre directors and teachers. In distributed leadership enactment, centre directors and teachers have separate but interdependent responsibilities and tasks in pedagogical leadership. This involves teachers as active facilitators of pedagogical reflection, learning and development in their teams and at the centre in a broad sense (Colmer et al., 2015). The National Core Curriculum for Early Childhood Education and Care (EDUFI, 2016) also demands building a working culture in which all ECE professionals learn and develop pedagogical practice together. Research (Heikka et al., 2018; Waniganayake et al., 2018) indicates that teachers have the power to inhibit or nourish pedagogical improvement in their teams. ECE teachers differentiate in relation to their skills and commitment to lead the team to critical reflection and learning or to encourage the participation of child care nurses in planning and assessment. Waniganayake et al. (2018) have noted that teachers' abilities to listen to child care nurses' observations of children enrich reflexivity in the team. Reflective practices are connected to a team's ability to develop practices.

The final dimension, developing strategy for distributed pedagogical leadership, is based on evidence that the enactment of distributed leadership should be well-planned, goal-oriented, and assessed and developed regularly (Heikka et al., 2013). Leaders have to create efficient structures and practices of distributed leadership and enhance the participation of staff in informal positions. The strategy for distributed pedagogical leadership makes leadership procedures and responsibilities explicit for professionals. A plan and a set of procedures for the establishment of shared organisational visions and strategies are essential, as is the determination of functions, tools and procedures for leadership evaluation and development. For this reason, it is important to study how the ECE professionals, ECE centre directors, ECE teachers and ECE child care nurses perceive the enactment of distributed pedagogical leadership in ECE centres.

In summary, distributed pedagogical leadership involves multiple persons enacting leadership, particularly in relation to pedagogy, and in interdependent ways throughout the ECE centre contexts. This requires the examination of leadership enactment as well as factors which influence the implementation of leadership (Spillane, 2006).

This small-scale study aimed at identifying the functions of distributed pedagogical leadership in ECE. As this study focused on distributed leadership approaches, it was more interested in the functions and the enactment of leadership rather than the roles or characteristics of the leaders. The functions of pedagogical leadership are distributed between the centre directors and the teachers through ECE centre contexts and leadership tools. Therefore, this study aimed at understanding how the interdependencies were created between the leadership enactments by the centre directors and ECE teachers. Based on this, the research questions of this study were as follows: How do ECE professionals, namely ECE centre directors, ECE teachers and ECE child care nurses, perceive the functions of distributed pedagogical leadership in ECE? And secondly, how the interdependencies between the leadership enactments by the centre directors and the teachers were created in ECE centres?

\section{METHODOLOGY}

The data was collected via six semi-structured theme interviews and written documents collected from the participants. The research was carried out in a medium-sized town in 
Finland between 2016 and 2018. The data collection was completed as part of a research project specifically designed to support the launch of the new National Core Curriculum for Early Childhood Education and Care (EDUFI, 2016) and its implementation. The study participants were selected purposefully to represent three different professional groups of ECE, namely ECE centre directors, ECE teachers and child care nurses. Two participants were selected from each group. These participants were selected to offer relevant information in relation to the research question because, due to their long-term experience, they were assumed to be able to provide informed insights into staff and leadership practices in the centres. The participants represented three municipal ECE centres.

The semi-structured theme interview method (Hirsjärvi \& Hurme, 2010) was employed for data collection. This approach is similar to the focused interview (Merton, Fiske, \& Kendall, 1990) and the general interview guide approach (Patton, 2002). However, it differs from the former in that all individual experiences, thoughts and beliefs can be investigated by the application of the theme interview, and there is no prerequisite for a collective experiment-based experience (Hirsjärvi \& Hurme, 2010). The interview participants were professionals of the research topic and, thus, were familiar with the concepts expressed in the interview and were experts in their field. Five interview themes were formulated based on the dimensions of distributed pedagogical leadership for the interview (Heikka, 2014). Along with the interviews, written documents were collected from the participants regarding their perceptions of distributed pedagogical leadership and teacher leadership in their settings following the interviews. The participants were asked to freely describe their perceptions of the concepts and their enactments in their settings.

The interview data and written documents were analysed using inductive qualitative content analysis (Patton, 2002). The analysis consisted of three phases. An inquiry into the substantive content of the transcribed interview data was performed separately among the three professional groups in the first phase. The condensed data was grouped to enable parallel investigations into professional group perspectives in the second phase. The categorisation that was formulated based on the analysis in the second phase was then utilised when working with the document data. Thirdly, the findings from the analysis of the document data were combined with the findings from the analysis of the interviews to cross-examine the two data sets. The document data strengthened the findings from the interviews and provided clearly described perceptions of the concepts under examination. New categories were not formulated in this phase.

\section{FINDINGS}

The study identified five functions of distributed pedagogical leadership in ECE. The functions were formulated based on the analysis of the experiences of ECE professionals on leadership enactment by the centre directors and the ECE teachers within their centres. The findings revealed that leadership of the centre directors and the teachers were enacted separately, but interdependently, at different levels of the centre's functioning. The identified functions of distributed pedagogical leadership were: constructing shared visions, goals and values for ECE; developing ECE pedagogy; facilitating learning and expertise of educators; building the operational structures and the culture of the centre; enhancing efficient and participatory decision-making. The centre directors operated on the whole centre level, whereas ECE teachers led pedagogy aligned with their own staff teams and child groups. The presentation of findings of leadership functions and the 
description of their distributed enactment is organised below in five separate chapters. Constructing shared visions, goals and values for ECE

The first function of distributed pedagogical leadership in ECE was identified in this study as constructing shared visions, goals and values for ECE between the centre staff. The ECE directors participating in the study perceived shared visions, goals and values between the staff members as prerequisites for sound pedagogical development in ECE centres. It was stated by the directors that the centre cannot move forward before they all have the same understanding about a mutual basis for working. The analysis revealed that the directors and the teachers had separate tasks and responsibilities in enacting this leadership function. The interdependence between the leadership enactments were created between the centre directors and the teachers by shared discussions that were organised regularly in the centres and held also in daily informal encounters. Artefacts, such as curricula and agreements between staff created interdependence by aligning discussions of visions and goals. Interdependence also demanded active leading by the centre directors, such as guiding and intervening in pedagogical practices of the staff. In addition, the ECE teachers created interdependence by developing tools for pedagogical documentation.

The leadership operations by centre directors included the development of centrelevel visions and values by guiding and involving all educators in regular discussions. The National Core Curriculum for Early Childhood Education and Care formulated the frame for discussions. In mutual meetings between the staff, they familiarised themselves with the core curriculum and opened it up through the themes picked up from the national framework. Pedagogical discussion includes the pondering of common values and goals based on the national curriculum, current research, pedagogical documentation and deciding how these can be realised in the centre's pedagogical practice. The centre directors proposed ideas, questions and valued aspirations to the staff in these discussions and enhanced further development together with the staff in the centre. In the following excerpt the centre director describes how the national curriculum creates a frame for the construction of a shared vision for the centre:

'... and also that the staff work according to the national curriculum. It is a big goal, and in all areas. Not just in particular matters, but so that the child's participation and broad-based learning are realized, all this, including gender sensitivity..., all the goals that are included in the curriculum, it takes significant effort and it together comprises daily life at the centre.'

In addition to the regular discussions between the staff, the directors reported guiding the development of the vision in all communication they had with the staff. This included also assessment by observing proceedings and functioning of the teams in the child groups and driving the centre towards the common vision by advising and intervening. The directors highlighted the importance of goal-oriented pedagogical leadership in daily communication with the staff members, as well as the enhancement of the involvement of all staff members in achieving sound pedagogical vision and modes of operation. One director also saw it as important to overcome differences in perspectives between the staff members and to create mutual operation models in a more conscious way.

The teachers enacted pedagogical leadership in their own staff teams based on the agreements about the common vision and values related to the whole centre. The teachers discussed the prospects with their team members and created plans for pedagogical development. The teachers emphasised also the meaning of pedagogical documentation as a tool for construction of acknowledged and justified practices within their teams as 
indicated in following except by one teacher:

'...and pedagogical documentations is also helpful; it deepens the acknowledgement of the reasons for our ways of working and how things are connected with each other and what is behind our practices and the pedagogical goals within the centre.'

The interdependence of the leadership operations between the centre directors and the teachers was created as each team, led by the teachers, negotiated and documented how the agreed visions, goals and values was achieved in the teams work with the child group. According to the child care nurses, this also included that the ECE teachers indicated for the team members how the goals could be realised in specific activities. In this way, the teachers also shared their pedagogical knowledge within their teams, supported and guided the team members' pedagogical thinking and activities with the child group and individual children. The teacher also reported that it is important to be able to explain the goals of pedagogical practices also to parents so that they understand them and this demands that a teacher has a clear vision for ECE.

\section{Developing ECE centre's pedagogy}

The findings revealed that pedagogical development was one core function of distributed pedagogical leadership within ECE centres. According to the studied professionals, the development of the pedagogical work within the centre demanded distribution of responsibilities between centre directors and the teachers. Both the ECE centre directors and the teachers took care of pedagogical development within the centres by taking care of it on the centre and team levels, respectively. The centre directors' responsibilities in pedagogical development included organising and guiding centre-level processes, for example regular pedagogical discussions and curriculum work. It was also seen that the centre directors bring the latest research knowledge to staff groups. The centre directors' duties included also the clarification of responsibilities among the educators within the centre and the teams. The foundations of interdependence in pedagogical development between the centre directors and the teachers was created through clear leadership structures as the roles and the responsibilities of the teachers and the distribution of responsibilities were mutually acknowledged and rechecked annually among the staff in the centres.

All the studied professionals perceived that teachers are in charge in their teams and have responsibility for pedagogical development in their teams. The creation of interdependence between the centre directors and the teachers was evident as it was stated by all the studied professionals that the pedagogical responsibility of the teachers includes ensuring that their teams act and develop towards the goals set for the centre and the particular child group. The findings revealed that the teachers developed pedagogy in their teams by facilitating development-based pedagogical planning, documentation and pedagogical discussion. According to the centre directors, the teachers have a clear grasp of supervision of work in a group.

The teachers and nurses felt that they have clearly defined roles within the teams. They agreed that responsibilities differentiate between the team members according to educational backgrounds, which brings together different kinds of knowledge and statuses in a group. In the following except, the centre director describes the teacher's significance 
for pedagogical development in the teams and for the creation of interdependence in pedagogical development within a centre:

'So, regarding development in the team and bringing it forward, I think that it will start from our shared discussions within the centre and from our shared visions, and then the teacher's interest and real and proper dialog with the team members. So that each member in the team knows what, how and why and understand their roles clearly. Even though they are equal, they have their own clear roles.'

The studied professionals perceived that the pedagogical development by the ECE teachers includes assessment of pedagogy and updating the ECE plans based on that. According to teachers, their pedagogical responsibility in assessment included the creation of a pedagogical documentation system to support pedagogical decisions and improvement of different pedagogical actions. All professionals emphasised everyone's responsibility to observe the educators and the children's actions and activities in the group. Nurses are told to pass their observations on to a teacher, who compiles these observations and writes them down in the group's and individual's ECE plans.

In pedagogical planning, teachers introduce their plans and materials to the nurses, and educators consider their suitability and functionality for different age groups together and enact plans in practice. Pedagogical planning by the teachers included also exploiting everyone's skills and knowledge in the different pedagogical activities. The child care nurse also stated that they propose ideas and felt that teachers listen to the nurses' ideas and integrate them into pedagogical plans and proceedings of the child group.

In addition, it was reported that teachers' capability to organise work is essential, as it has an effect on the practical functioning of the team. On the other hand, if the leadership of the team is ambiguous and teamwork is disorganised, it will create a sense of rush and distress among the educator team. However, the director felt that ECE teachers cannot take responsibility or act as the leaders of their team in every case. Some teachers are not capable of organising their own or a team's work properly, as can be seen in the following except:

'If it is weak, for example the organisation of teamwork and leading one's own work, it causes immediate anxiety and a feeling of being rushed: I haven't had time to do this and I haven't had time to do that and haven't time to do that either. But if it is balanced, the duties are handled well.'

The centre director also emphasized the importance of pedagogical expertise of the teachers in pedagogical development. A strong ECE teacher's identity and an interest in developing one's work can assist teachers to take responsibility and develop pedagogy.

\section{Facilitating learning and expertise of educators}

To facilitate learning and increase expertise of the educators was perceived as a significant function of distributed pedagogical leadership according to the study participants. This included that the centre directors organised regular meetings for the centre staff, in which they could participate in shared reflection on pedagogical practices and the learning activities aimed at deepening the educators' knowledge about a particular chosen subject. In these discussions, the centre directors challenged the staff's pedagogical thinking and facilitated development of new ideas and knowledge among staff. In this way, the centre directors guided the educators' discussions about how they can improve and encouraged 
the centre staff to be more courageous to try new approaches in pedagogy. The director gives tips and inspire staff to think pedagogically and in a more far-reaching way.

According to the centre directors, their facilitation of shared reflection was based on the National Core Curriculum for Early Childhood Education and Care, which was seen to contribute to the educators' expertise in this way and to formulate a basis for assessment of the centre's pedagogy together with the staff. It was perceived by the centre director, that in addition to the regular meetings with the staff, maintaining staff learning demands daily conversations, observations and reflection together.

Shared pedagogical reflection was perceived as essential among the study participants, as it was reported to assists educators to evaluate pedagogical practices also within their child groups and help them make decisions on how the practices can be improved. It also aligned the focus of pedagogical evaluation and development in the child groups and created interdependence between the leadership enactments on the centre and team levels in this way. Teachers felt the centre directors' guidance in reflection and their support for developing their pedagogical thinking and leadership in the teams was essential. The directors and ECE teachers encouraged and guided nurses' pedagogical reflection by discussing with them, listening to them, sharing their own viewpoints and providing knowledge about contemporary topics, yet trusting the teams' own decisions about pedagogy. The centre directors also distributed the responsibility to the teachers to facilitate the nurses' learning by giving tasks and topics for discussion.

The child care nurses felt that they received guidance and support for their pedagogical work and reflection from the teacher. They felt that the ECE teachers led reflection in a respective way, not overruling their actions, but by asking questions and providing tips for developing and improving. The nurses reported that in weekly team meetings, educators discussed the current topics and goals, shared ideas, and reflected on and assessed their own actions. Teachers enhanced nurses' learning and their participation in pedagogical planning and assessment and provided assistance when needed. The reflection in the team meetings is based on educators' observations on children's performances in pedagogical activities and discussing the reasons behind matters. Pedagogical reflection is then utilized in pedagogical planning and development, which can be seen in the following excerpt by the child care nurse:

\begin{abstract}
In our weekly team meetings, once we have completed something, we think about it by asking simple questions about how we experienced something and if something could have been done differently. By asking these kinds of simple questions and discussing and reflecting on whether an idea was good, evaluating how the children experienced something and what kind of feedback they gave, or what they didn't like about it, we gain knowledge for the future. We better understand if we have presented something in an inappropriate way or if we managed to facilitate issues for children. In this way we learn.'
\end{abstract}

According to the ECE teacher, they also reflect the pedagogical activities on a daily basis and analyse specific situations occurring in the child group. In addition, the ECE teacher guides nurses in terms of daily pedagogical documentation and reflection, and assists them in learning new pedagogical approaches by asking questions and acting as a model in daily activities with children. These processes led by the teachers created interdependence in the leadership enactments as it formulated a continuum for the educators' practise-based learning. However, the teacher felt that there should be more pedagogical reflection and assessment by all educators in the ECE centre. 


\section{Developing the operational structures and the culture of the centre}

One function of distributed pedagogical leadership was to develop the operational structures and the culture of the centre. Within this function, the centre directors and ECE teachers share the responsibility for generating goal-oriented functioning and developing the operational culture, which aims to enact the curricula in centres.

Developing the operational structures and the culture of the centres included making a plan for pedagogical leadership by the centre directors. The plans were essential for creating interdependence between the leadership enactments. In the plans, along with the pedagogical goals, the structures, for example, the responsibilities of the staff members, the schedules and the contents of the meetings and the processes for leading pedagogy, was opened and made visible for the staff. The teachers perceived that in this way, and especially as the director was rarely present at the ECE centre, the plan for distributed pedagogical leadership supports the centre's functioning.

In the plans for pedagogical leadership, the goals and procedures for the team's operations were designed. This included the roles and responsibilities of the team members and the organisation of teamwork, which according to the study participants was perceived to strengthen teachers' leadership positions and functions within the groups, which can be seen in the following excerpt by the centre director:

It includes a clear plan for the organisation of the teamwork and leading the work in the teams and of course the teacher's positions and promotion of it.'

The director stated that the goals are useful for an ECE teacher as they guide child care nurses to support teachers and comply with the core curriculum. The director perceived that when members work well together in the teams, it contributes to collegial support, especially through communication. The director thought that well-being at work increases when the responsibilities are clear, and work is well organised:

If the team work, when it is properly organised, and by organising work, work well-being is increased and will clarify workers' roles.'

Organising teamwork in an ECE centre is particularly important in a centre where the directors reported noticing a difference in ECE teachers' pedagogical expertise and in the way they take charge in their teams. The director considered that along with the plan for pedagogical leadership, the job descriptions of different professionals affect how pedagogical leadership is enacted by different professionals at different levels of the organisation.

Pedagogical leadership was distributed for the teachers also by organising the regular teachers' meetings, where they convene and discuss current topics in education and plan and evaluate pedagogical activities. In ECE teachers' pedagogical meetings, teachers get support from each other and can engage in discussion before they bring new ideas and knowledge to their teams. In addition to teachers' meetings, there were the weekly whole centre meetings and the weekly team meetings. 


\title{
Enhancing efficient and participative decision-making
}

Achieving efficient and participative decision-making within centres as a function of distributed pedagogical leadership was linked to maintaining the balance between pedagogical and managerial duties in the centre directors' work. The centre directors considered that decision processes related to their managerial duties differ from decisions processes related to pedagogy and pedagogical changes. It was perceived that for achieving efficiency in decision-making, a shared negotiation is demanded for decisions related to pedagogical practices because it is crucial to receive shared understanding between centre staff about why such changes are needed and decide together with the staff how the centre should proceed towards a common vision. This also included, according to the directors, the decisions to intervene in situations where educator work conflicts with what is agreed within a centre. However, one centre director stated that in shared decisionmaking with the educators, a director needs to acknowledge one's own responsibilities, status and authority.

The adjustment of the decision-making processes between individual and shared provided efficiency in decision-making also when the directors could use their authority to make individual decisions related to centres' daily management and administration. The directors' management skills make individual decision-making easier and faster and thus afford more time for pedagogical leading and its development. In the following excerpt, the centre director reflects on the development of her management skills and how it created time for pedagogical leadership and development in the centre:

\begin{abstract}
'At the beginning of my career, it felt like the management duties would take me away totally, because it was a new area for me. But I had to learn to cope with it and it took my energy...but now it feels that the managerial duties work as a routine, and it leaves time and energy for pedagogical leadership and development.'
\end{abstract}

Along with the shared decision-making within the centre, the decision-making was distributed between centre directors and the teachers as the teachers made decisions about pedagogy in their own child groups. The interdependence between the leadership decisions made by the centre directors and the teachers was created as the teachers reported that the decisions about pedagogy, pedagogical development and intervening in the team members' ways of working was based on the visions and goals discussed with the whole ECE centre community. The centre directors reported that distributing decisionmaking related to pedagogy to teachers in their centres is based on trusting the teachers' expertise and their ability to take and bear responsibility for their child groups. According to teachers, the decisions included also intervening and shared reflection in situations where someone in their teams seems to be acting differently than what is expected, as can be seen in the following excerpt:

'Quite often I bring issues up in the team meetings, that the problem is in this bit, and what if we do it like this. Then we start to try new ways of working. Then they start to think about it and I ask whether we will start to do it so, yes, and then we adjust it so that it is appropriate for the children's age and think about how we can apply it in our child group.' 
The teachers felt that they are trusted by the centre directors, and that within their teams it is acceptable to intervene or question the way the nurses act in certain situations with children. This also included actions by the teachers in verbalising and explaining the decisions and their backgrounds to the team members.

\section{CONCLUSIONS}

This study identified five functions of distributed pedagogical leadership and indicated how these functions were enacted between ECE centre directors and ECE teachers separately, but interdependently within centres. Within all the five functions of distributed pedagogical leadership, the leadership enactment included responsibilities at both the centre level enacted by the centre directors, and at the team level enacted by the ECE teachers. Constructing shared visions, goals and mutual values within centres formulated a base for all leadership functions as several affirmative notes in the analysis were made showing how shared visions enabled the sufficient enactment of the other leadership functions. Similarly, according to Sims et al. (2015), the essence of distributed leadership is the mutual understanding of meaning of the organisation by all staff members.

The findings also indicated that the prerequisites for interdependence were created by a clear strategy for distributed pedagogical leadership created by the centre directors within centres. This included efficient structures for pedagogical development, organisation of shared pedagogical reflection between centre staff and clarification of the roles and responsibilities of the team members. This was evidenced as critical for enhancing the learning of the educators.

The study clearly indicated that the teachers played an active role in leading pedagogical development in their teams, and teacher leadership worked as a mediator of pedagogical leadership within the whole centre. In the daily functioning of the centre directors and the teachers, the interdependence between the leadership enactments was created by shared discussions, artefacts and tools, structures as well as by parallel leadership operations at the centre and in the teams. Similarly, Spillane et al. (2001) emphasise the meaning of structures, tools and routines in distributed leadership. Furthermore, Spillane et al. (2003) and Spillane (2006) state that leadership tools, like curricula and observation documents, guide the enactment of leadership and could be seen as elements of leadership. This was inevitable in this study as the national curriculum and the observation documents seemed to build a bonding frame for the leadership enactment in the centre and the teams. The interdependencies between the centre directors and the teachers seemed to be realized as "collective distribution" (Spillane, 2006, p. 60) as the centre directors and the teachers were mainly working separately but interdependently enabling each other's work in achieving common goals. Similarly, Denee and Thornton (2018) concluded that effective leaders supported distributed leadership by trusting and providing opportunities for teachers to participate in leadership and decision-making. In addition, the directors in this study were actively adapting their decision-making processes to include staff in decision-making when needed, and they also made quick decisions on administrative issues to allocate more time for pedagogical leadership.

The findings of this study implicate that the enactment of pedagogical leadership functions as distributed between the centre directors and the teachers in early childhood centres assist in the achievement of efficient implementation of pedagogical leadership. Well-organised distribution of leadership functions clarify and align daily co-operation within centres and the staff teams and build the conditions for professional learning of 
educators. In addition, clear leadership structures assist also all, not just persons, who work as formal or informal leaders, to take on positive attitude towards leaders and their work. The limitations of this study were mainly the small number of participants from each professional group. As a result, this study does not attempt to depict a general picture of distributed pedagogical leadership in ECE, but rather provides in-depth insight into the leadership enactments by the study participants.

\section{REFERENCES}

Act 540/2018. Varhaiskasvatuslaki. [Act on Early Childhood Education]. https://www.finlex.fi/fi/laki/alkup/2018/20180540

Alila, K., Eskelinen, M., Estola, E., Kahiluoto, T., Kinos, J., Pekuri, H.-M,...Lamberg, K. (2014). Varhaiskasvatuksen historia, nykytila ja kehittämisen suuntalinjat. Tausta-aineisto varhaiskasvatusta koskevaa lainsäädäntöä valmistelevan työryhmän tueksi. Opetus- ja kulttuuriministeriön työryhmämuistioita ja selvityksiä 2014:12. [The history, presence and the directions for the development. Survey for the Early Childhood Education Act Working Committee. Ministry of Education and Culture memorandums and surveys 2014:12]. Retrieved from http://urn.fi/URN:ISBN:978-952-263-266-1

Aubrey, C. (2016). Leadership in early childhood. In D. Couchenour \& J. Kent Chrisman (Eds.), The Sage Encyclopedia of Contemporary Early Childhood Education (pp. 808-810). Thousand Oaks, CA: Sage Publications.

Boe, M., \& Hognestad, K. (2017). Directing and facilitating distributed pedagogical leadership: Best practices in early childhood education. International Journal of Leadership in Education, 20(2), 133148. doi: 10.1080/13603124.2015.1059488

Colmer, K., Waniganayake, M., \& Field, L. (2015). Implementing curriculum reform: Insights on how Australian early childhood directors view professional development and learning. Professional Development in Education -Special Issue: The Professional Development of Early Years Educators, 41(2), 203-221. doi: 10.1080/19415257.2014.986815

Denee, R., \& Thornton, K. (2018). Distributed leadership in ECE: perceptions and practices. Early Years: An International Research Journal. Advance online publication. doi: 10.1080/09575146.2018.1539702

EDUFI (2016). National Core Curriculum for Early Childhood Education and Care. Finnish National Board of Education.

Halttunen, L. (2009). Päivähoitotyö ja johtajuus hajautetussa organisaatiossa [Day Care work and leadership in a distributed organization]. (Doctoral dissertation, University of Jyväskylä, Jyväskylä, Finland). Retrieved from https://jyx.jyu.fi/dspace/bitstream/handle/123456789/22480/9789513937621.pdf

Harris, A. (2003). Teacher leadership as distributed leadership: Heresy, fantasy or possibility. School Leadership \& Management, 23(3), 313-324. doi: 10.1080/1363243032000112801

Heikka, J. (2014). Distributed Pedagogical Leadership in Early Childhood Education (Doctoral dissertation). Acta Electronica Universitatis Tamperensis 1392. University of Tampere, Tampere: Tampere University Press.

Heikka, J., Halttunen, L., \& Waniganayake, M. (2016). Investigating teacher leadership in ECE centres in Finland. Journal of Early Childhood Education Research, 5(2), 289-309.

Heikka, J., Halttunen, L., \& Waniganayake, M. (2018). Perceptions of early childhood education professionals on teacher leadership in Finland. Early Child Development and Care, 188(2), 143-156. doi: 10.1080/03004430.2016.1207066

Heikka, J., \& Hujala, E. (2013). Early childhood leadership through the lens of distributed leadership. European Early Childhood Education Research Journal, 21(4), 568-580. doi: 10.1080/1350293X.2013.845444

Heikka, J., Waniganayake, M., \& Hujala, E. (2013). Contextualizing distributed leadership within early childhood education: Current understandings, research evidence and future challenges. Educational Management, Administration \& Leadership, 41(4), 30-44. doi: 10.1177/1741143212462700

Hirsjärvi, S., \& Hurme, H. (2010). Tutkimushaastattelu: Teemahaastattelun teoria ja käytäntö [Research interview: Theory and practise of the theme interview]. Helsinki: Helsinki University Press.

Ho, D. C. W. (2011). Identifying leadership roles for quality in early childhood education programmes. International Journal of Leadership in Education, 14(1), 47-57. doi: 10.1080/13603120903387561 
Hognestad, K., \& Boe, M. (2014). Knowledge development through hybrid leadership practices. Nordisk Barnehageforskning, 8(6), 1-14. Retrieved from http://dx.doi.org/10.7577/nbf.492

Hognestad, K., \& Boe, M. (2015). Leading site-based knowledge development: A mission impossible? Insights from a study from Norway. In M. Waniganayake, J. Rodd \& L. Gibbs (Eds.), Thinking and learning about leadership. Early childhood research from Australia, Finland and Norway (pp. 210228). Sydney: Community Child Care Cooperative NSW.

Male, T., \& Palaiologou, I. (2017). Pedagogical leadership in action: Two case studies in English schools. International Journal of Leadership in Education, 20(6), 733-748. doi: 10.1080/13603124.2016.1174310.

Merton, R. K., Fiske, M., \& Kendall, P. L. (1990). The focused interview. A manual of problems and procedures. Glencoe, IL: Free press.

Patton, M. Q. (2002). Qualitative research and evaluation methods (3d ed.) Thousand Oaks (Calif.): Sage.

Sims, M., Forrest, R., Semann, A., \& Slattery, C. (2015). Conceptions of early childhood leadership: Driving new professionalism? International Journal of Leadership in Education, 18(2), 149-166. doi: $10.1080 / 13603124.2014 .962101$

Spillane, J.P. (2006). Distributed Leadership. San Francisco, CA: Jossey-Bass.

Spillane, J.P., Halverson, R., \& Diamond, J.B. (2001). Investigating school leadership practice: A distributed perspective. Educational Researcher, 30(3), 23-28.

Spillane, J.P., Diamond, J.B., \& Jita, L. (2003). Leading instruction: the distribution of leadership for instruction. Journal of Curriculum Studies, 35(5), 533-543.

Waniganayake, M., Cheeseman, S., Fenech, M., Hadley, F., \& Shepherd, W. (2017). Leadership: Contexts and complexities in early childhood education. (2nd ed.). South Melbourne: Oxford University Press.

Waniganayake, M., Heikka, J., \& Halttunen, L. (2018). Enacting pedagogical leadership within small teams in early childhood settings in Finland - Reflections on system-wide considerations. In S. Cheeseman \& R. Walker (Eds.), Volume 1 in the series on Thinking about pedagogy in early education: Pedagogies for leading practice (pp. 147-164). A. Fleet \& M. Reed (series editors). Oxon: Routledge.

Waniganayake, M., Rodd, J., \& Gibbs, L. (Eds.). (2015). Thinking and learning about leadership: Early childhood research from Australia, Finland and Norway. Sydney: Community Child Care Cooperative NSW.

York-Barr, J., \& K. Duke. (2004). What do we know about teacher leadership? Findings from two decades of scholarships. Review of Educational Research, 74(3), 255-316. doi: 10.3102/003465430740. 